\title{
Evolução de Biomarcadores de Estresse \\ Oxidativo e Relação com a Performance \\ Competitiva em Dois Momentos da \\ Temporada de Treinamento de Natação
}

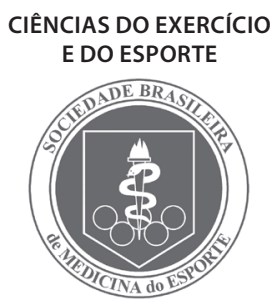

Artigo Original

\section{Evolution of Oxidative Stress Biomarkers and Correlation with Competitive Performance in Two Moments of the Swimming Training Season}

\author{
Rafael Deminice \\ Gabriel Carvalho Degiovanni ${ }^{1}$ \\ Monike Ribeiro Garlipp-Picchi ${ }^{1}$ \\ Mariana T. Nóbrega' \\ Marcelo Teixeira ${ }^{2}$ \\ Alceu Afonso Jordão

\section{Laboratório de Nutrição e Metabolismo, Faculdade de Medicina de Ribeirão Preto - USP. \\ Universidade de Ribeirão Preto - UNAERP.} \\ 2. Equipe de natação da
}

Endereço para correspondência: Alceu Afonso Jordão

Laboratório de Nutrição e

Metabolismo, Faculdade de

Medicina de Ribeirão Preto - USP.

Av. Bandeirantes, 3.900 - Monte

Alegre

14049-900 - Ribeirão Preto, SP.

E-mail: alceu@fmrp.usp.br

Submetido em 14/06/2008

Versão final recebida em 06/09/2008

Aceito em 07/12/2008

\begin{abstract}
RESUMO
Introdução: Estudos têm demonstrado aumento na formação de espécies reativas de oxigênio após o esforço físico intenso. Esses eventos podem aumentar a suscetibilidade das células musculares a danos oxidativos como a peroxidação lipídica. Assim, variações na intensidade e no volume de treinamento durante a temporada podem modular o metabolismo oxidativo e influenciar a performance dos atletas. Objetivo: Estudar a evolução de biomarcadores de peroxidação lipídica em dois momentos de um ciclo periodizado de treinamento e relacionar com a performance competitiva de natação. Métodos: Participaram do presente estudo 16 nadadores (nove do gênero masculino e sete do feminino). Amostras de sangue foram coletadas em dois períodos do ciclo de treinamento: período preparatório específico e período de polimento. Espécies reativas ao ácido tiobarbitúrico (TBARS) e peróxidos totais foram determinados como biomarcadores de peroxidação lípidica. Creatina quinase foi determinada como parâmetro de dano celular muscular. O índice técnico alcançado no estilo de especialidade de cada atleta foi utilizado como parâmetro de performance competitiva. O índice técnico foi determinado na competição preparatória Troféu Electro Bonini realizada no período preparatório específico, e no Campeonato Paulista realizado no final do período de polimento. Resultados: Foi encontrado aumento significativo $(p<0,05)$ no índice técnico no Campeonato Paulista (769,6 $\pm 51,1$ pontos) em relação ao Troféu Electro Bonini (751,1 $\pm 55,7$ pontos). Significativas reduções na concentração de TBARS $(5,7 \pm 2,9$ vs 3,3 $\pm 2,2 \mu \mathrm{mol} / \mathrm{L})$ e peróxidos totais $(45,1 \pm 20,6$ vs $29,6 \pm 13,0$, $\mu \mathrm{mol}$ $\left.\mathrm{H}_{2} \mathrm{O}_{2} / L\right)$ foram encontrados no período de polimento com relação ao período preparatório específico. $\mathrm{O}$ mesmo não foi encontrado para creatina quinase (123,6 $\pm 60,1$ vs 137,4 $\pm 74,9 \mathrm{U} / \mathrm{L})$. Conclusão: A significativa diminuição nos biomarcadores de peroxidação lipídica decorrente do decréscimo no volume e intensidade do treinamento após o período de polimento demonstra a influência das variações do treinamento sobre o estresse oxidativo e sua possível relação com a performance.
\end{abstract}

Palavras-chave: peroxidação lipídica, treinamento, performance, nadadores.

\begin{abstract}
Introduction: Studies have shown increase in the formation of oxygen reactive species after intense physical exertion. These events may increase the susceptibility of muscular cells to oxidative damage such as lipid peroxidation. Thus, variations in training intensity as well as volume during the season may modulate the oxidative stress and influence in performance of athletes. Aim: To study the evolution of lipid peroxidation biomarkers in two moments of a periodized cycle of training and correlate it with swimming competitive performance. Methods: 16 swimmers participated in this study ( 9 males and 7 females). Blood samples were collected in two periods of the training cycle: specific preparation training and tapering period. Species reactive to thiobarbituric acid (TBARS) and total peroxides were determined as lipid peroxidation biomarkers. Creatine kinase was determined as a parameter of muscular cell damage. The technical index reached in the style of specialization of each athlete was used as a competitive performance parameter. The technical index was determined in the preparatory competition Trophy Electro Bonini carried out in the specific preparatory period and in the Championship of São Paulo State carried out in the end of the tapering period (769.6 \pm 51.1 points) in comparison with the Trophy Electro Bonini (751.1 \pm 55.7 points). Significant reductions In the TBARS concentration ((5.7 \pm $2.9 \mathrm{vs} 3.3 \pm 2.2 \mu \mathrm{mol} / \mathrm{L}$ ) and total peroxides ( $45.1 \pm 20.6 \mathrm{vs} 29.6 \pm 13.0 \mu \mathrm{mol}_{2} \mathrm{O}_{2} / \mathrm{L}$ ) were found In the tapering period concerning the specific preparatory period. The same situation was not found for creatine kinase ((123.6 \pm 60.1 vs $137.4 \pm 74.9 \mathrm{U} / \mathrm{L})$. Conclusion: The significant decrease in the biomarkers of lipid peroxidation derived from the decrease in the volume and intensity of training after the tapering training demonstrates the influence of the training variations on the oxidative stress and its possible relation with performance.
\end{abstract}

Keywords: lipid peroxidation, training, performance, swimmers. 


\section{INTRODUÇÃO}

A formação de espécies reativas de oxigênio e radicais livres ocorre no metabolismo celular normal; entretanto, pode estar aumentada em condições de estresse físico, promovendo estado de estresse oxidativo(1). Estresse oxidativo é a condição na qual a produção celular de radicais livres e espécies reativas de oxigênio excede a capacidade fisiológica do sistema de defesa antioxidante em remover esses compostos ${ }^{(2)}$. Nos últimos anos, estudos têm mostrado a ação dos exercícios aeróbios e anaeróbios em diversas situações e modalidades esportivas em promover a formação de espécies reativas de oxigênio e aumentar o estresse oxidativo(3-7). Bloomer ${ }^{(7)}$ relata que a formação de espécies reativas de oxigênio pode participar da iniciação e progressão do dano na fibra muscular, pela promoção de diversos eventos, como a peroxidação lipídica, iniciação de processos inflamatórios e oxidação de proteínas, mecanismos esses que podem afetar proteínas estruturais e contráteis e contribuir para queda da performance muscular.

Durante a temporada, variações no volume, intensidade e frequência de treino são programadas para promover a adaptação fisiológica necessária no organismo do atleta ${ }^{(8)}$. Assim, os programas atuais de treinamento alternam períodos de treino intenso seguido de período précompetição, caracterizado por redução na carga de treinamento com o objetivo de otimizar a performance ${ }^{(9)}$. Nos últimos anos, autores têm relatado modulações no estresse oxidativo induzidos por mudanças na carga de treinamento, principalmente no período pré-competição, conhecido como polimento(10-13). Entretanto, pouco conhecidas são as possíveis relações entre tais modificações na dinâmica de biomarcadores de estresse oxidativo e a performance competitiva ${ }^{(12)}$. É hipótese do presente estudo que redução de biomarcadores de estresse oxidativo decorrentes da redução da carga de treinamento no período de polimento pode influenciar a performance em natação. Ainda, autores têm demonstrado a significativa relação entre biomarcadores de estresse oxidativo determinados durante a temporada de treinamento e o estado de supertreinamento ${ }^{(13-15)}$. Finaud et al. ${ }^{(13)}$ relatam a necessidade de estudos empenhados em investigar a evolução do estresse oxidativo durante a temporada de treinamento como parâmetros importantes na determinação da saúde, nutrição e performance de atletas.

O objetivo do presente estudo foi verificar a evolução de biomarcadores de peroxidação lipídica em dois momentos de um ciclo periodizado de treinamento e relacionar com a performance competitiva em natação.

\section{MÉTODOS}

\section{Participantes}

Foram participantes voluntários do presente estudo 16 nadadores (nove do gênero masculino e sete do feminino), idade de 18,1 \pm 2,6 anos, todos pertencentes à equipe de natação da Universidade de Ribeirão Preto-SP, Brasil. Após aprovação do projeto em questão pelo Comitê de Ética em Pesquisa da Faculdade de Medicina de Ribeirão Preto-USP, os voluntários foram informados sobre os objetivos e possíveis riscos envolvidos no estudo e assinaram um termo de consentimento. Os atletas realizavam treinamento regular havia mais de cinco anos e todos participavam de competições de nível estadual e nacional. As características antropométricas e exames bioquímicos dos atletas estão apresentadas na tabela 1.

\section{Procedimentos}

O estudo foi realizado durante a temporada preparatória para o Campeonato Paulista de Inverno (primeiro semestre de 2007). Dados antropométricos foram colhidos e coletas de sangue realizadas em dois momentos distintos da temporada: período preparatório específico e
Tabela 1. Características antropométricas e bioquímicas dos atletas estudados $(n=16)$.

\begin{tabular}{l|c|c}
\hline & $\begin{array}{c}\text { Período preparatório } \\
\text { específico }\end{array}$ & $\begin{array}{c}\text { Período de } \\
\text { polimento }\end{array}$ \\
\hline Estatura (m) & $1,78 \pm 4,9$ & $1,78 \pm 4,8$ \\
\hline Peso (kg) & $70,9 \pm 11,1$ & $71,6 \pm 10,2$ \\
\hline Gordura corporal (\%) & $13,3 \pm 2,1$ & $12,5 \pm 2,7$ \\
\hline Glicemia (mg/dL) & $74 \pm 3,9$ & $77,5 \pm 6,1$ \\
\hline Colesterol total (mg/dL) & $148,1 \pm 56,5$ & $167,3 \pm 28,4$ \\
\hline LDL (mg/dL) & $90,2 \pm 55,7$ & $102,7 \pm 34,8$ \\
\hline HDL (mg/dL) & $45,5 \pm 9,1$ & $48,7 \pm 11,5$ \\
\hline Triglicérides (mg/dL) & $62,3 \pm 21,4$ & $81,2 \pm 35,4^{*}$ \\
\hline
\end{tabular}

${ }^{*} p<0,05$ com relação ao período preparatório específico.

período de polimento. O programa de treinamento foi todo elaborado pelo técnico da equipe e não sofreu nenhum tipo de intervenção por parte dos pesquisadores e procedimentos experimentais. O volume e a intensidade do treinamento foram anotados e quantificados para cada período (figura 1). Duas competições realizadas dentro da temporada foram utilizadas como parâmetro de performance. O torneio preparatório de nível regional Troféu Electro Bonini realizado no meio do período preparatório específico e o Campeonato Paulista, ao final do período de polimento. As duas competições foram realizadas em piscina semiolímpica de 25 metros.

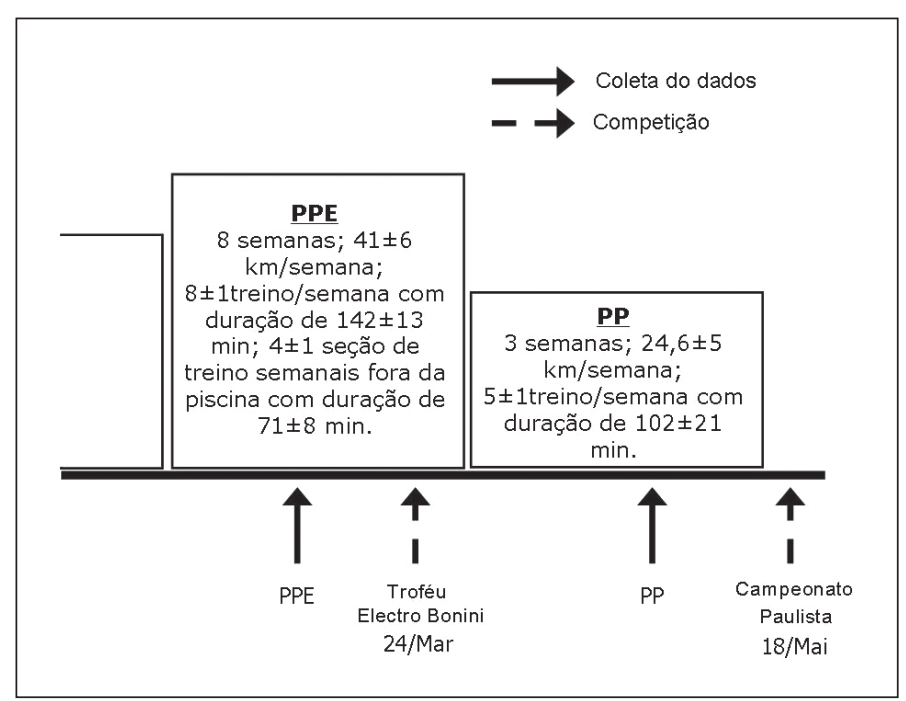

Figura 1. Representação esquemática dos procedimentos experimentais (PPE: período preparatório específico; PP: período de polimento).

Em cada período específico da temporada de treinamento citado acima, cada participante foi convidado a se apresentar no laboratório no início da manhã para coleta de dados antropométricos e de sangue. Uma balança Filizola ${ }^{\circledR}$ com estadiômetro acoplado foi utilizada para a mensuração de peso e estatura. A gordura corporal foi determinada por impedância bioelétrica (Byodinamics BIA 310E). O sangue venoso de jejum de cada atleta foi coletado em tubos Vacutainer ${ }^{\circledR}$. Os tubos foram mantidos no escuro e refrigerados a $4^{\circ} \mathrm{C}$ até o final do teste e posteriormente centrifugados a 3.000 rpm por 10 min para separação do soro. 


\section{Métodos laboratoriais}

Espécies reativas ao acido tiobarbitúrico (TBARS) foi determinado no soro através do método descrito por Costa et al.(16). Peróxidos totais ( $\mathrm{LOOH})$ foram determinados no soro de acordo com Södergren et al.(17). Ambos foram utilizados como biomarcadores de peroxidação lipídica.

Para determinação de TBARS, $200 \mu \mathrm{L}$ de soro foram misturados a $2 \mathrm{~mL}$ de solução contendo $15 \%$ de acido tricloroacético, 0,38\% de ácido tiobarbitúrico e 0,25N de ácido clorídrico. A mistura foi encubada a $100^{\circ} \mathrm{C}$ por 30 minutos e, após centrifugação de 10 minutos a 3.000 rpm, a absorbância foi mensurada a $535 \mathrm{~nm}$ em espectrofotômetro (UV-Vis Mod Q98U Quimis ${ }^{\circledR}$, Diadema, Brasil). TBARS total foi determinada pela diferença de absorbância entre as amostras e curva padrão de MDA. Os resultados foram expressos em $\mu \mathrm{mol} / \mathrm{L}$.

Peróxido total foi determinado pelo método férrico-xilenol orange, onde $1 \mathrm{~mL}$ de solução contendo $100 \mu \mathrm{mol} / \mathrm{L}$ de xilenol orange, $4 \mathrm{mmol} / \mathrm{L}$ $\mathrm{BHT}, 25 \mathrm{mmol} / \mathrm{L}$ de ácido sulfúrico e $250 \mu \mathrm{mol} / \mathrm{L}$ de sulfato ferroso em metanol:água (9:1 v/v) foi adicionada a uma alíquota de 100 $\mu \mathrm{L}$ de soro. Após agitar e encubar por 30 min em temperatura ambiente, o homogenato foi centrifugado por 10 min a 3.000rpm. A absorbância do sobrenadante foi lida a 560nm e comparado com curva padrão de peróxido de hidrogênio $\left(\mathrm{H}_{2} \mathrm{O}_{2}\right)$ em espectrofotômetro (Uv-Vis Mod Q98U Quimis ${ }^{\circledR}$, Diadema, Brasil). Os resultados foram expressos em 13,0umol $\mathrm{H}_{2} \mathrm{O}_{2} / \mathrm{L}$.

Creatina quinase $(\mathrm{U} / \mathrm{L})$ foi determinada no soro a partir de kit Labtest ${ }^{\circledR}$.

\section{Índice técnico como parâmetro de performance (IPS)}

A performance competitiva foi mensurada através do International Point Score nas provas de especialidade de cada atleta (dois atletas no $50 \mathrm{~m}$ livre, quatro no $100 \mathrm{~m}$ livre, um no $200 \mathrm{~m}$ livre, um no $400 \mathrm{~m}$ livre, um no 100 costas, quatro no $100 \mathrm{~m}$ peito, dois no $100 \mathrm{~m}$ borboleta e um no 200m medley). Tal escore é parte do sistema da FINA (Fédération Internationale de Natation Amateur) e permite comparar a performance dos nadadores independente do gênero nos diferentes estilos da natação (livre, costas, peito, borboleta e medley individual). Tal sistema de pontuação é baseado nos tempos dos oito melhores atletas de todos os tempos em cada modalidade da natação (podendo atingir no máximo 1.000 pontos). O sistema International Point Score pode ser encontrado em http://www.fina.org/swimming/FINApoints/index.php.

\section{Análise estatística}

Os valores foram expressos em média \pm desvio padrão. $O$ teste $t$ de Student para amostras pareadas foi utilizado para determinar possíveis diferenças entre as variáveis bioquímicas e de performance nos dois períodos de treinamento e de competição. O coeficiente de correlação de Pearson foi utilizado para verificar possíveis associações entre as variáveis estudadas. Em todos os casos o nível de significância foi prefixado para $\mathrm{p}<0,05$.

\section{RESULTADOS}

A figura 2 apresenta os valores de International Point Score nas duas competições disputadas durante a temporada de treinamento. Os resultados demonstram aumento significativo na performance no Campeonato Paulista (769,6 \pm 51,1 pontos) com relação ao Troféu Electro Bonini $(751,1 \pm 55,7$ pontos $)$.

Na figura 3 estão apresentados os biomarcadores de peroxidação lipídica determinados nos dois períodos de treinamento estudados. Foram encontradas reduções significativas nas concentrações séricas de $\operatorname{TBARS}(5,7 \pm 2,7$ vs $3,3 \pm 2,1 \mu \mathrm{mol} / \mathrm{L})$ e peróxidos totais $(45,1 \pm 20,6$ vs $29,6 \pm 13,0$ umol $\mathrm{H}_{2} \mathrm{O}_{2} / \mathrm{L}$ ) no período de polimento quando comparado com período preparatório específico. Esses resultados demonstram a modulação do estresse oxidativo induzida pelo treinamento.

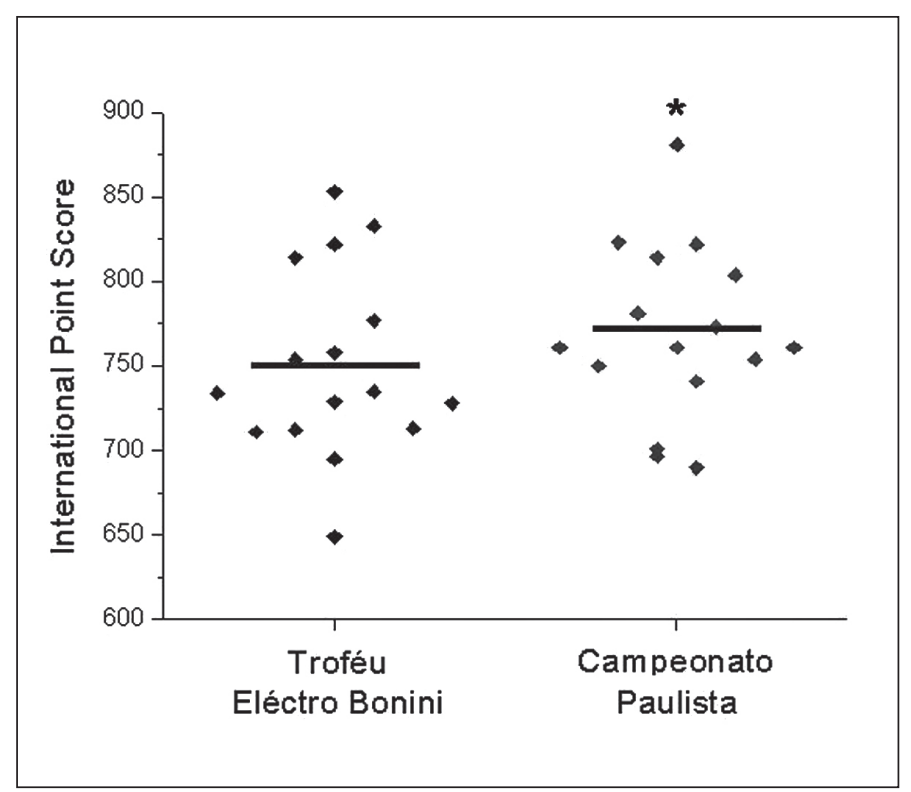

Figura 2. International Point Score como parâmetro de performance nas competições Troféu Electro Bonini e Campeonato Paulista ( ${ }^{*} t$ de Student demonstrando diferença significativa, $p<0,05)$
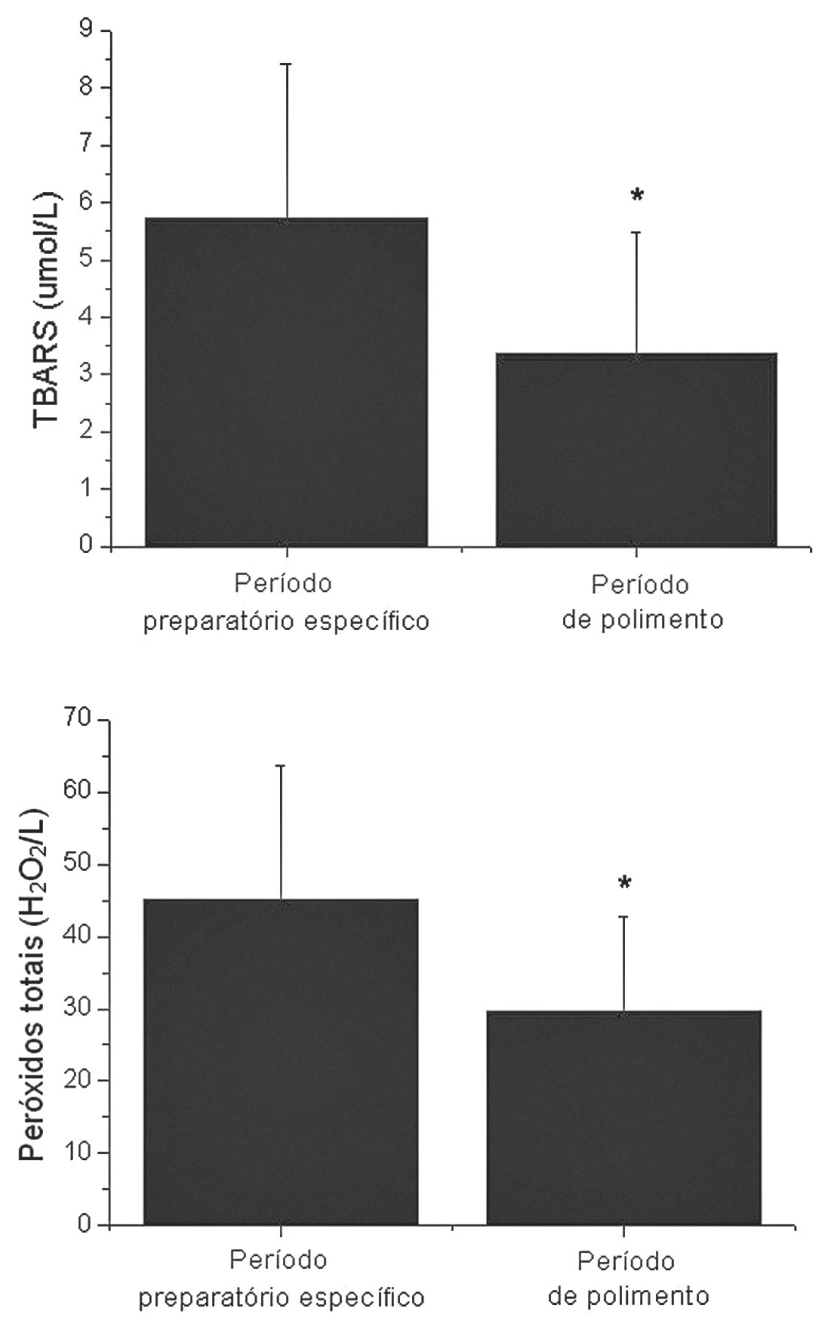

Figura 3. Concentrações séricas de TBARS (acima) e peróxidos totais (abaixo) como biomarcadores de peroxidação lipídica nos períodos preparatório específico e polimento ${ }^{*} t$ de Student demonstrando diferença significativa, $p<0,05$ ). 
O mesmo não foi encontrado com relação à creatina quinase (131,1 $\pm 64,1$ vs 141,1 $\pm 73,3 \mathrm{U} / \mathrm{L}$ ) entre os períodos estudados (figura 4).

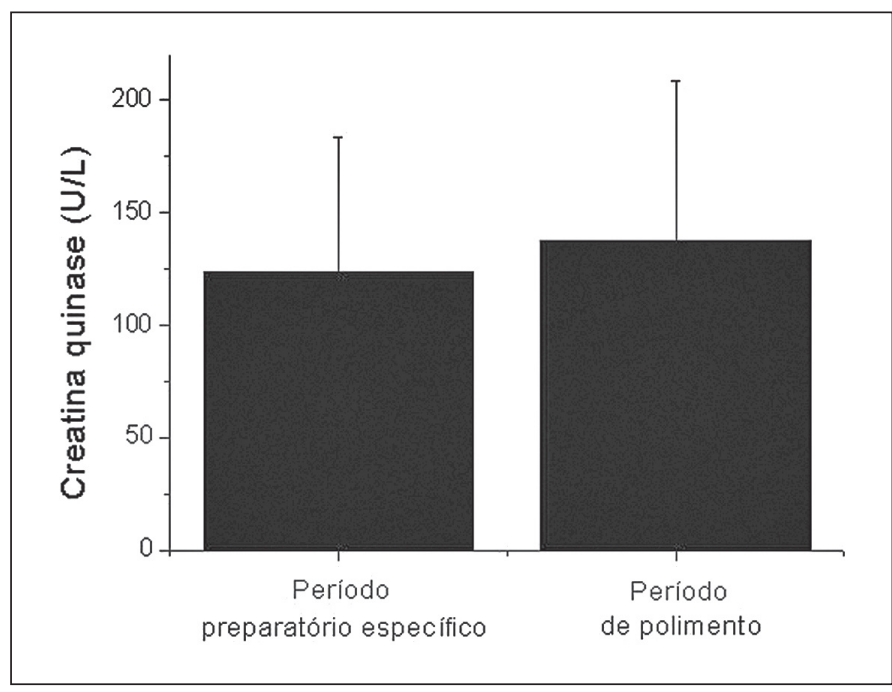

Figura 4. Concentração sérica de creatina quinase como biomarcador de dano muscular nos períodos preparatório específico e polimento

Na tabela 2 estão apresentados os coeficientes de correlação de Pearson entre as variações $(\triangle)$ dos parâmetros de performance (IPS), peroxidação lipídica (TBARS e LOOH) e dano muscular (creatina quinase, CK). Não foram encontradas significativas correlações de TBARS e peróxidos totais com IPS. Correlação significativa foi encontrada entre TBARS e creatina quinase (CK).

Tabela 2. Coeficiente de correlação de Pearson entre a variação dos parâmetros de performance, peroxidação lípidica e dano celular muscular.

\begin{tabular}{l|c|c|c|c}
\hline & $\Delta \mathrm{IPS}$ & $\Delta \mathrm{TBARS}$ & $\Delta \mathrm{LOOH}$ & $\Delta \mathrm{CK}$ \\
\hline$\Delta \mathrm{IPS}$ & 1 & & & \\
\hline$\Delta$ TBARS & 0,33 & 1 & & \\
\hline$\Delta$ LOOH & 0,12 & 0,24 & 1 & \\
\hline$\Delta \mathrm{CK}$ & $-0,06$ & $0,59^{*}$ & $-0,16$ & 1 \\
\hline
\end{tabular}

${ }^{*} \mathrm{p}<0,05$ (IPS: International Point Score; TBARS: espécies reativas ao ácido tiobarbitúrico; LOOH: peróxidos totais; CK: creatina quinase).

\section{DISCUSSÃO}

A temporada de treinamento de natação é caracterizada por mudanças na interação dos componentes: intensidade, volume e frequência de treinamento, com o objetivo de promover adaptações fisiológicas, metabólicas e psicológicas específicas no organismo do atleta ${ }^{(8)}$. O período pré-competição ou período de polimento é caracterizado por redução na carga de treinamento nos dias que antecedem uma competição importante, com o objetivo principal de aumentar a performance $e^{(9,18)}$. Na busca da maximização do processo de polimento, técnicos e estudiosos têm relacionado significativas melhoras na performance às mudanças em parâmetros fisiológicos ${ }^{(19-21)}$, psicológicos ${ }^{(22)}$ e técnicos ${ }^{(23)}$ após esse período.

Os resultados do presente estudo demonstraram que três semanas de polimento com redução de aproximadamente $60 \%$ na carga de treinamento foram capazes de aumentar a performance competitiva dos atletas em suas provas de especialidade (figura 2). Tal melhora foi acompanhada por significativas reduções nas concentrações de TBARS e peróxido total (figura 3). Alguns estudos também têm encontrado mudanças em biomarcadores de estresse oxidativo decorrentes por mudanças no volume e/ou intensidades de treinamento durante a temporada ${ }^{(11,13,24-26)}$. Schippinger et al. ${ }^{(11)}$ encontraram significativo aumento na concentração de marcadores de estresse oxidativo (peróxidos totais) no período competitivo comparado com a pré-temporada em jogadores de futebol americano. Palazzetti et al.(25) demonstraram que quatro semanas de treinamento intenso são capazes de aumentar parâmetros de estresse oxidativo e dano celular (TBARS e creatina quinase), além de diminuir a capacidade antioxidante. Finaud et al.(13) encontraram significativo aumento no estresse oxidativo associado à diminuição na eficiência do sistema de defesa antioxidante em períodos de alta intensidade em jogadores de rúgbi durante a temporada. Em contrapartida, períodos de menor intensidade de treinamento induziram diminuições em parâmetros de estresse oxidativo, inflamação e dano celular muscular. Esses autores ainda sugerem que marcadores do metabolismo oxidativo podem ser utilizados como parâmetros biológicos para monitorar a evolução do treinamento de atletas de nível competitivo.

No entanto, poucos desses estudos objetivaram relacionar a modulação de parâmetros de estresse oxidativo diretamente com a performance competitiva. Margonis et al. ${ }^{(15)}$ encontraram significativa redução nos biomarcadores de estresse oxidativo (TBARS, carbonilas e isoprostanos), além da significativa resposta antioxidante (GSH/GSSG, (at, GPx e TAC) acompanhando a redução da carga de treinamento após 12 semanas de musculação. Esses autores ainda encontraram significativas correlações entre a variação do volume de exercício durante o período de treinamento e de parâmetros de performance (1RM e potência no teste de Wingate) e biomarcadores de estresse oxidativo (isoprostano e GSH/GSSG); concluem que o treinamento intenso induz mudanças nos biomarcadores de estresse oxidativo e respostas do sistema antioxidante, e, em alguns casos, essas modulações são proporcionais à carga de treino e podem influenciar a performance. No presente estudo, apesar de não encontradas correlações entre a variação nos biomarcadores de peroxidação lipídica e performance, os resultados demonstram a significativa ação do período de polimento sobre a performance competitiva e reforçam a hipótese de que a redução de biomarcadores de estresse oxidativo induzida pela redução da carga de treinamento nesse período pode ser parte importante na evolução da performance. A diminuição da concentração desses marcadores pode representar a minimização de eventos oxidativos e inflamatórios, como infiltração de leucócitos e macrófagos, ativação da enzima xantina oxidase bem como processo de isquemia e reperfusão, eventos esses que promovem oxidação de proteínas contráteis e danos na membrana celular muscular ${ }^{(15)}$. No presente estudo, a significativa correlação encontrada entre a variação de TBARS e creatina quinase demonstra a ligação entre tais processos.

Os antioxidantes também podem desempenhar importante papel nesses processos e, como consequência, estar relacionado com a performance. Essas substâncias funcionam como sistema de defesa, atenuando modificações oxidativas provocadas pelo treinamento intenso ou promovendo a recuperação mais rápida ${ }^{(7)}$. Assim, substâncias e enzimas do sistema de defesa antioxidantes também podem representar promissores marcadores do estado de treinamento e da performance competitiva.

Contudo, autores ainda têm encontrado resultados controversos com relação às mudanças no metabolismo oxidativo induzido pela intensidade de treino e sua possível relação com a melhora da performance. Subudhi et al. ${ }^{(24)}$, em estudo com corredores da seleção americana 
de esqui alpino, concluíram que elevações nos marcadores de estresse oxidativo não foram evidentes, apesar da significativa diminuição do estado antioxidante após o período de uma semana de treinamento intenso. Vollaard et al. ${ }^{(12)}$, estudando triatletas, encontraram significativa melhora na performance de 15 minutos após duas semanas de polimento. Entretanto, tais melhoras na performance não foram acompanhadas pelo aumento do estresse oxidativo e redução na relação GSH/GSSG. Esses autores ainda concluem que a melhora na performance não pode ser associada às mudanças nos biomarcadores de estresse oxidativo decorrentes das variações dos períodos de treinamento.

Estudos recentes têm apontado marcadores de estresse oxidativo determinados no sangue ou na urina como promissores indicadores da síndrome do supertreinamento (SST $)^{(14,15)}$. SST é considerado um tipo de desordem fisiológica, metabólica e/ou psicológica caracterizada por significante redução na performance e fadiga excessiva decorrente do excesso de treinamento que afeta muitos atletas ${ }^{(12,15)}$. Fatouros et al.(27) e Margonis et al. ${ }^{(15)}$ encontraram significativas respostas inflamatórias, aumento do estresse oxidativo e deterioração na performance de força no período de treinamento intenso, em protocolo utilizado para indução da SST. Zoppi e Macedo ${ }^{(14)}$, estudando o estado de supertreinamento induzido por protocolo específico para ratos e sua relação com marcadores de estresse oxidativo, relatam que tal relação ainda é bastante controversa. Esses autores ainda concluem que a SST induzida pelo aumento do estresse oxidativo é dependente do tipo de fibra muscular e sugerem a realização de es-

\section{REFERÊNCIAS BIBLIOGRÁFICAS}

1. Finaud J, Lac G, Filaire E. Oxidative stress: relationship with exercise and training. Sports Med 2006:36(4):327-58.

2. Bloomer RJ, Goldfarb AH. Anaerobic exercise and oxidative stress: a review. Can J Appl Physiol 2004;29(3):245-63.

3. Souza JrTP, Oliveira PR, Pereira B. Efeitos do exercício físico intenso sobre a quimioliminescencia urinária e malonaldeido plasmático. Rev Bras Med Esporte 2005;11(1):91-6.

4. Bloomer RJ, Goldfarb AH, Wideman L, McKenzie MJ, Consitt LA. Effects of acute aerobic and anaerobic exercise on blood markers of oxidative stress. J Strength Cond Res 2005;19(2):276-85.

5. Paschalis V, Nikolaidis MG, Fatouros IG, Giakas G, Koutedakis Y, Karatzaferi C, et al. Uniform and prolonged changes in blood oxidative stress after muscle-damaging exercise. In Vivo 2007;21(5):877-83.

6. Cuevas MJ, Almar M, García-Glez JC, García-López D, De Paz JA, Alvear-Ordenes I, et al. Changes in oxidative stress markers and NF-kappaB activation induced by sprint exercise. Free Radic Res 2005;39(4):431-9.

7. Bloomer RJ. The role of nutritional supplements in the prevention and treatment of resistance exerciseinduced skeletal muscle injury. Sports Med 2007;37(6):519-32.

8. Maglischo EW. Nadando ainda mais rápido. $1^{\text {a }}$ nd. ed. Manole: São Paulo, 1999.

9. Bosquet L, Montpetit J, Arvisais D, Mujika I. Effects of tapering on performance: a meta-analysis. Med Sci Sports Exerc 2007;39(8):1358-65.

10. Child RB, Wilkinson DM, Fallowfield JL. Effects of a training taper on tissue damage indices, serum antioxidant capacity and half-marathon running performance. Int J Sports Med 2000;21(5):325-31.

11. Schippinger G, Wonisch W, Abuja PM, Fankhauser F, Winklhofer-Roob BM, Halwachs G. Lipid peroxidation and antioxidant status in professional American football players during competition. Eur J Clin Invest 2002;32(9):686-92.

12. Vollaard NB, Cooper CE, Shearman JP. Exercise-induced oxidative stress in overload training and tapering. Med Sci Sports Exerc 2006;38(7):1335-41.

13. Finaud J, Scislowski V, Lac G, Durand D, Vidalin H, Robert A, et al. Antioxidant status and oxidative stress in professional rugby players: evolution throughout a season. Int J Sports Med 2006;27(2):87-93.

14. Zoppi CC, Macedo DV. Overreaching-induced oxidative stress, enhanced HSP72 expression, antioxidant and oxidative enzymes downregulation. Scand J Med Sci Sports 2008;18(1):67-76.

15. Margonis K, Fatouros IG, Jamurtas AZ, Nikolaidis MG, Douroudos I, Chatzinikolaou A, et al. Oxidative tudos para elucidar essa relação. Margonis et al.(15) relatam que estudos futuros devem observar a sensibilidade e especificidade desses parâmetros durante a temporada de treinamento, além de controlar fatores interferentes como a alimentação habitual dos atletas.

A partir dos resultados obtidos, podemos concluir que as significativas diminuições nos marcadores de peroxidação lipídica, decorrente do decréscimo no volume e intensidade do treinamento após o período de polimento, coincidem com o significativo aumento da performance em nadadores de nível competitivo. Esses dados sugerem a significativa influência das variações do treinamento no metabolismo oxidativo e sua possível relação com a performance. Estudos futuros devem ser direcionados a determinar a sensibilidade e especificidade dos biomarcadores de estresse oxidativo durante a temporada de treinamento, com o intuído de detectar o estado de supertreinamento por possíveis variações individuais nesses marcadores, em tempo para intervenção, antes da deterioração da saúde e da performance competitiva do atleta.

\section{AGRADECIMENTOS}

Apoio financeiro da Fapesp (Fundação de Amparo à Pesquisa do Estado de São Paulo. Proc. 04/13893-4).

Todos os autores declararam não haver qualquer potencial conflito de interesses referente a este artigo. stress biomarkers responses to physical overtraining: implications for diagnosis. Free Radic Biol Med 2007:43(6):901-10.

16. Costa CM, Dos Santos RCC, Lima E. A simple automated procedure for thiol measurement in human and serum samples. J Braz Patol Med Lab 2006;42:345-50.

17. Södergren E, Nourooz-Zadeh J, Berglund L, Vessby B. Re-evaluation of the ferrous oxidation in xylenol orange assay for the measurement of plasma lipid hydroperoxides. J Biochem Biophys Methods 1998;18;37(3):137-46.

18. Mujika I, Padilla S. Scientific bases for precompetition tapering strategies. Med Sci Sports Exerc 2003:35(7):1182-7.

19. Bonifazi M, Sardella F, Lupo C. Preparatory versus main competitions: differences in performances, lactate responses and pre-competition plasma cortisol concentrations in elite male swimmers. Eur J Appl Physiol 2000;82(5-6):368-73.

20. Mujika I, Padilla S, Pyne D, Busso T. Physiological changes associated with the pre-event taper in athletes. Sports Med 2004;34(13):891-927.

21. Papoti M, Martins LE, Cunha SA, Zagatto AM, Gobatto CA. Effects of taper on swimming force and swimmer performance after an experimental ten-week training program. J Strength Cond Res 2007;21(2):538-42.

22. Hooper SL, Mackinnon LT, Howard A. Physiological and psychometric variables for monitoring recovery during tapering for major competition. Med Sci Sports Exerc 1999;31(8):1205-10.

23. Trinity JD, Pahnke MD, Reese EC, Coyle EF. Maximal mechanical power during a taper in elite swimmers. Med Sci Sports Exerc 2006;38(9):1643-9.

24. Subudhi AW, Davis SL, Kipp RW, Askew EW. Antioxidant status and oxidative stress in elite alpine ski racers. Int J Sport Nutr Exerc Metab 2001;11(1):32-41.

25. Palazzetti S, Richard MJ, Favier A, Margaritis I. Overloaded training increases exercise-induced oxidative stress and damage. Can J Appl Physiol 2003;28(4):588-604.

26. Lac G, Maso F. Biological markers for the follow-up of athletes throughout the training season. Pathol Biol (Paris) 2004;52(1):43-9.

27. Fatouros IG, Destouni A, Margonis K, Jamurtas AZ, Vrettou C, Kouretas D, et al. Cell-free plasma DNA as a novel marker of aseptic inflammation severity related to exercise overtraining. Clin Chem 2006;52(9):1820-4. 